\title{
Impact of Consumer Innovativeness on Shopping Styles: A Case-Study of Limkokwing University Students (Botswana)
}

\author{
Olumide Olasimbo Jaiyeoba (Corresponding author) \\ Department of Marketing, Faculty of Business, University of Botswana, Botswana \\ E-mail: olujaiyeoba@yahoo.com
}

Frederick Odongo Opeda

Faculty of Business \& Globalization, Limkokwing University, Gaborone, Botswana

E-mail: Fopedas@limkokwing.ac.bw

Received: Nov. 9, 2013 Accepted: Dec. 7, $2013 \quad$ Published: Dec. 12, 2013

doi:10.5296/bmh.v1i2.4733 URL: http://dx.doi.org/10.5296/bmh.v1i2.4733

\begin{abstract}
The unprecedented abundance of choice and retail outlets creates a massive array of choice for consumers most especially students. Innovative consumers are an important market segment. This paper seeks to investigate whether consumers' innate innovativeness is associated with their shopping styles. Specifically, it aims to explore the relationship between two types of innovativeness (sensory innovativeness and cognitive innovativeness and consumer shopping styles). Indeed, the unprecedented abundance of choice and retail outlets creates a massive array of choice for consumers. Despite these significant changes in the commercial environment, very little is known about the decision making processes of consumers in developing countries, most especially in Botswana. Ostensibly, the paucity of research in this area hinders our understanding of consumer decision making processes. The paper integrates the consumer innovativeness and consumer shopping styles literature. A structural equation model was used to test the relationship between cognitive and sensory innovativeness and various shopping styles. Cognitive innovators are inclined to show shopping styles such as quality consciousness, price consciousness, and confusion by overchoice, while sensory innovators are inclined to have shopping styles such as brand consciousness, fashion consciousness, recreational orientation, impulsive shopping, and brand loyalty/habitual shopping. The research is based on a convenience sample of young
\end{abstract}




\section{Macrothink}

Business and Management Horizons

ISSN 2326-0297

2013, Vol. 1, No. 2

consumers in Botswana. The findings of this research would hopefully help managers to develop a deeper insight into product development and marketing. Furthermore, since the youth market in Botswana represents an enormous opportunity for marketers, the paper provides valuable insights into this key market segment. It thus provides new insights into the shopping patterns of consumers who belong to different innovativeness types. It also makes a new contribution to the shopping styles literature by explicating potential antecedents to the various shopping styles among the largest private tertiary institution students in Botswana.

Keywords: Consumer behaviour, Innovation, Shopping, Decision making, Limkokwing University students, Botswana 


\section{Introduction}

Consumer decision making style can be defined as a mental orientation characterizing a consumer's approach to making choices (Sproles and Kendall, 1986). Innovative consumers are an important market segment for marketers. Revenue from new products adopted by innovative consumers is an important market segment for marketers. Revenue from new products adopted by innovative consumers play a pivotal role for many firms (Cowart et al., 2008). Although consumer decision making style represents a relative consistent pattern of cognitive and affective responses (Bennett and Kassarjian, 1972), national culture has been proven to impact significantly on individual values and attitudes (Hofstede, 1980). Thus, culture is expected to have a significant influence on consumer decision making style. In particular, this paper examines and adds evidence to the specific culture of Botswana, most especially among Tertiary students. This could help consumer behaviour researchers gain a deeper understanding of consumers' shopping behaviour and assist marketing managers in approaching consumers more efficiently by targeting specific consumer clusters or segments (Lysonski et al., 1996).

In the face of a rapidly changing competitive environment characterized by overchoice, excessive marketing communications, sophisticated and complex products, decreasing interbrand difference, and increasing counterfeiting and look-alike products, some consumers, most especially University students, feel overwhelmed and find it difficult to decide. A particular study that has increasingly received attention is the differentiation between cognitive and sensory innovativeness made by Venkatraman and Price (1990). Cognitive (sensory) innovativeness is the preference for engaging in new experiences with the objective of stimulating the mind (senses). Although researchers have showed interest in such a differentiation (Im et al., 2007), there is little empirical research on shopping patterns of consumers who belong to these two innovativeness types. A rare example is a study by Hirunyawipada and Paswan (2006), who investigated high-tech products adoption behaviour using the cognitive and sensory innovativeness constructs. This study, however intends to investigate the effective cognitive and sensory innovativeness on decision making styles of Limkokwing University of Creative Technology (LUCT), students in Botswana. As would be discussed in detail later in this paper, understanding potential differences in shopping styles between these two types of innovative consumers would be an important part of successful marketing strategy when innovative consumers are the primary target segment. Thus, the main goal of this research is to gain deeper understanding into potential differences in shopping styles of these two different types of innovative consumers in the largest private tertiary institution in Botswana.

Another goal of this study is therefore to bring more clarity to the understanding of consumer decision making styles by examining its additional antecedent, specifically the impact of consumer innovativeness (Hirschman, 1980). Testing the relationship between a more parsimonious version of the early original instrument developed by Sproles and Kendall (1986) called Consumer Style Inventory (CSI) and consumer innate innovativeness could provide rich information that facilitates the understanding of consumers' motivation in their consumption choice as well as profiling University consumer segment in Botswana. 


\section{Literature Review and Hypotheses Development}

The Consumer Style Inventory (CSI) developed by Sproles and Kendall (1986) has been the most tested instrument currently available to measure decision making styles. Sproles and Kendall (1986) view this construct as basic consumer personality analogous to the concept of personality in psychology. Research on this construct can be categorized into three main approaches: the consumer typology approach (Darden and Ashton, 1974; Moschis, 1976); the psychographics lifestyle approach (Lastovicka, 1982); and the consumer characteristics approach (Sproles, 1985; Sproles and Kendall, 1986; Sproles and Sproles, 1990). The unifying theme among these three approaches is the tenet that all consumers engage in shopping with certain fundamental decision making modes or styles including rational shopping, consciousness regarding brand, price and quality among others. Among these three approaches, however, the consumer characteristics approach seems to be the most powerful and explanatory since it focuses on the mental orientation of consumers in making decisions. As such this approach deals with cognitive and affective orientations of consumers in their process of decision making. It assumes that decision making styles can be determined by identifying general orientations towards shopping and buying. It is useful to marketers since it provides a quatitative instrument for classifying heterogeneous decision making styles among consumers into discrete categories of orientation. Such knowledge is also useful in terms of identifying segments or clusters of consumers sharing similar orientations to shopping.

Many studies of CSI have focused on replications of the Sproles and Kendall (1986) study in various countries most especially developed countries, however, few studies attempt to explore the antecedents and consequences of CSI styles (Wesley et al., 2006). Consumer innovativeness is viewed as the predisposition to search for and buy new and different products and brands rather than simply adhering to accepted consumption patterns (Hirschman, 1980; Venkatraman, 1991; Venkatraman and Price, 1990). Whereas consumer innovativeness is generalizable across a variety of product and service categories (Steenkamp et al., 1999). Midgley and Dowling (1978) cautioned that consumer innovativeness may be influenced by a variety of factors, such as marketing efforts, characteristics of innovation itself and consumer demographics. Moreover, Venkatraman (1991) has argued that consumer innovativeness is linked to the desire for new and different experiences rather than new product adoption behaviour. Venkatraman and Price (1990) concluded that both cognitive and sensory stimulation are relevant to consumer innovativeness captured through cognitive and innate components respectively. Innovativeness has been conceptualized and measured in a number of ways. Extant literature has defined consumer innovativeness in several ways. Most researchers in consumer innovativeness have investigated commonality of early adopters. Several investigators have considered this willingness to try new products or services to be a generalized readiness that cuts across a number of product or service classes (e.g., Alkinet et al., 1998; Rangaswamy and Gupta, 1999). Such a dimension of innovativeness that is generalized across several domains has been found, however, to have rather limited association with the adoption of a specific innovation. 
Consumer innovativeness is considered as the tendency to willingly embrace change and try new things (Cotte and Wood, 2004), the degree to which an individual is relatively earlier in adopting an innovation than others (Rogers and Shoemaker, 1971), and buying new products more often and more quickly than others (Roehrich, 2004). Owing to inconsistent findings in the literature of consumer innovativeness, a hierarchical perspective of consumer innovativeness is proposed by Hirunyawipada and Paswan (2006); global (personal trait): domain-specific (narrowly defined trait toward products category), and innovative behaviour. Global innovativeness, which is a construct of interest in this paper is a personality trait at the highest level of abstraction and independent of domain or product specific category. Consumer innovativeness is therefore a useful variable to divide value based segments in order to accurately direct marketing efforts. This paper, thus contributes, to that understanding. Although many researchers have theorized global innovativeness trait as a single construct, others suggest it to be multidimensional, including sensory and cognitive traits (i.e., Venkatramana and Price, 1990). Cognitive innovators enjoy thinking, problem solving, puzzling over issues and other mental exertions, and they seek new experiences that stimulate these mental activities. Sensory innovativeness in contrast, is the preference for new experiences that stimulate the senses. Some innovative people have a preference for either cognitive or sensory stimulation, but others may seek both (Hirschman, 1984; Venkatraman and MacInnis, 1985).

Cognitive consumers monitor a greater number of mass media vehicles, have a greater tendency to read package information, newspaper and magazines advertisements and do more exploration through shopping such as browsing at window displays (Hirschman, 1984; Venkatraman and MacInnis, 1985). Extant literature however explicate that consumer innovativeness demonstrates that cognitive and sensory consumers differ in their ethnic backgrounds, demographic profiles, information search behaviours, and the way of attitude formation. Sheth et al. (1991), concluded that consumption value theory can be applied to understanding consumer choices for a wide range of product categories. Therefore, this study investigates interaction effect of consumer innovativeness as a personal characteristic and consumption value so that an in-depth understanding of consumption value and its relationship to purchase intentions can be established.

One of the consequences of differentiating cognitive and sensory innovativeness is that consumers who have these different predispositions may have different decision-making styles (Venkatraman and Price, 1990). Following this argument, we hypothesize that different innate innovation characteristics styles. According to Sproles and Kendall (1986), their empirical study identified eight mental characteristics describing a consumer's decision making style from 40 CSI statements. These eight styles (quality conscious, brand conscious, fashion conscious, recreational and hedonistic orientation, price consciousness, impulsive and careless tendencies, confused by overchoice, and brand loyalty) describe the most basic mental characteristics of a consumer's decision making, which are directly linked to consumer choice behaviour. Such knowledge is also essential in identifying segments of consumers sharing similar attitudes to shopping (Lysonski et al., 1996). Accordingly, we propose that consumers with the higher tendency of cognitive innovativeness will show 
quality and price consciousness and confusion by overchoice in their shopping styles. We thus hypothesize that:

H1: Consumers who have predispositions toward cognitive innovativeness are inclined to have decision making styles of quality, price consciousness and confusion by overchoice.

Sensory innovators enjoy novelty, tend to have a light-hearted and easy going attitude towards life, take risks and do things that give them pleasure without too much thinking or deliberation (Zuckerman, 1979). Accordingly, we propose that consumers with the higher tendency of sensory innovativeness will show brand consciousness, fashion consciousness, recreational orientation, impulsiveness, and habitual/brand loyal orientation in their shopping styles. Such a description matches well with the other five shopping styles from CSI. Consumers scoring high on the novelty and fashion consciousness shopping styles are likely to gain excitement and pleasure from seeking out new things through shopping (Zuckerman, 1979). Sproles and Kendall (1986) concluded that consumers with recreational and hedonistic shopping consciousness style possess the trait to find shopping pleasant, and shop just for fun of it and they consider shopping for recreation and entertainment. We thus hypothesize that:

H2: Consumers who have predispositions toward sensory innovativeness are inclined to have decision making styles of brand consciousness, fashion consciousness, recreational orientation, impulsiveness and habitual/brand loyal orientation.

\section{Methods}

The consumer decision making style was measured by the purified CSI scales to measure the eight consumer decision making styles (Sproles and Kendall, 1986), innovativeness scales to measure cognitive and sensory innovativeness (Venkatraman and Price, 1990). The scales used here are seven point Likert scales from 1 (strongly disagree) to 7 (strongly agree). The parsimonious version of the scale items consist of 39 items from the original Sproles \& Kendall study of the CSI and 16 items from the Venkatraman and Price study of consumer innovativeness. Botswana is one of the fastest growing markets with increasing purchasing power and diversity of market segments has necessitated the need for this study, even though most studies were conducted in developed economies. The statistics of Cronbach alpha and item to total correlations was undertaken to assess the internal consistency of the instrument.

To examine the applicability of the instrument, the analysis investigated the psychometric properties of the CSI. First, the dimensionality of the consumer styles inventory was examined by examining the factor solution (Gerbing and Anderson, 1988). In essence, the amount of variance explained by the extracted factors (i.e., their Eigen values) was recorded. Additionally, item-factor correlations (i.e., factor loading) and other indices of model adequacy were examined. Principal components factor analysis with a varimax rotation was used to obtain the factor solution which is consistent with the analytic procedure used by Sproles and Kendall (1986). The final sample consisted of 330 usable responses and there are 207 females and 123 males. Student samples are especially appropriate for this study for several reasons. First, people with college degrees are among the most affluent consumers in Botswana. They live in urban areas, and they will soon be part of an important group of 
consumers that marketers are eager to satisfy. Secondly, most of the past studies that used the CSI including the original Sproles and Kendall,(1986), have relied on student samples. The current study, thus explicate insightful comparisons with past research in this area.

After eliminating items which represents non-significant factor loadings, high modification indices and high residuals, convergent validity was evident by all items significantly loading on their respective constructs, and the Confirmatory factor analysis (CFA) produced respectable fits: $\mathrm{X}^{2}=2.098, \mathrm{X}^{2} / \mathrm{df}$ scale reliabilities exceeded recommended thresholds and ranged from $0.66-0.87$. The analysis provides evidence for the hypothesized relationships among all the variables of interest. All of the hypothesized relationships between constructs are statistically significant, supporting both $\mathrm{HI}$ and $\mathrm{H} 2$. Cognitive innovativeness is positively related to shopping styles of quality consciousness $(\beta=0.54, p<0.001)$, price consciousness $(\beta=0.61, p<0.001)$ and confusion by overchoice $(\beta=0.59, \mathrm{p}<0.001)$ in support of H1a, H1b, and H1c. The data also provide evidence that sensory innovativeness is positively related to brand consciousness $(\beta=0.64, p<0.001)$, fashion consciousness $(\beta=0.57, \quad p<0.001)$, recreational orientation $(\beta=0.51, \quad p<0.001)$, impulsiveness $(\beta=0.59, \quad p<0.001)$, and habitual/brand loyal orientation $(\beta=0.74, \mathrm{p}<0.001)$ supporting $\mathrm{H} 2 \mathrm{a}, \mathrm{H} 2 \mathrm{~b}, \mathrm{H} 2 \mathrm{c}, \mathrm{H} 2 \mathrm{~d}$, and $\mathrm{H} 2 \mathrm{e}$.

\section{Conclusions and Managerial Implications}

Researchers in consumer behaviour tend to focus on the cognitive aspect of consumer innovativeness (Bagozzi and Foxall, 1996; Im et al., 2007). The insights from this research have important managerial implications. Bloch (1995) concluded that those who are more cognitively oriented may feel more strongly about the product's attributes and performance, as well as the degree of incongruity with existing products. On the other hand, the design and sensory properties of the product rather than its performance and functional attributes would help elicit aesthetic responses from the sensory consumer. While sensory innovator customers are inclined to show hedonic shopping styles such as brand consciousness, recreational orientation, fashion consciousness, impulsive shopping and habitual/brand loyal orientation. The cognitive innovators are inclined towards utilitarian aspects. Marketers therefore need to have a good understanding about how their products appeal to these different innovators, and come up with marketing plans to facilitate these plans. Cognitive innovators are most likely to focus on the utilitarian features of products, whereas sensory innovators may put more emphasis on the aesthetic aspects of products. Thus, one of the implications of our research is that, if consumers are indeed different in the extent to which they have cognitive and sensory dispositions, then we should have a closer look at how this could be related to their behavioural patterns as consumers. 
Table 1. Results of the hypotheses testing

\begin{tabular}{|c|c|c|c|c|c|}
\hline $\begin{array}{l}\text { Independent } \\
\text { Variable }\end{array}$ & \multicolumn{2}{|c|}{$\begin{array}{l}\text { Dependent } \\
\text { Variable }\end{array}$} & \multicolumn{2}{|c|}{$\begin{array}{l}\text { Standardized } \\
\text { Coefficients }\end{array}$} & Hypotheses \\
\hline Cognitive & \multicolumn{2}{|c|}{ Quality Conscious } & \multicolumn{2}{|c|}{$0.54 *$} & HIa Supported \\
\hline \multirow[t]{2}{*}{ Innovativeness } & \multicolumn{2}{|c|}{ Price conscious } & \multicolumn{2}{|l|}{$0.69 *$} & H1b Supported \\
\hline & \multicolumn{2}{|c|}{ Confused by overchoice } & \multicolumn{2}{|l|}{$0.60 *$} & H1c Supported \\
\hline Sensory & \multicolumn{2}{|c|}{ Brand } & \multicolumn{2}{|l|}{$0.64 *$} & H2a Supported \\
\hline \multirow[t]{4}{*}{ Innovativeness } & \multicolumn{2}{|l|}{ Fashion } & \multicolumn{2}{|l|}{$0.62 *$} & H2b Supported \\
\hline & \multicolumn{2}{|c|}{ Recreational } & \multicolumn{2}{|l|}{$0.55^{*}$} & H2c Supported \\
\hline & \multicolumn{2}{|c|}{ Impulsiveness } & \multicolumn{2}{|l|}{$0.59 *$} & H2d Supported \\
\hline & \multicolumn{2}{|c|}{ Habitual/Brand Loyal } & \multicolumn{2}{|l|}{$0.71 *$} & H2e Supported \\
\hline \multirow[t]{3}{*}{ Fit statistics } & & 2.098 & NNFI & 0.91 & \\
\hline & $2 / \mathrm{df}$ & 3.54 & CFI & 0.92 & \\
\hline & RMSEA & 0.063 & NFI & 0.89 & \\
\hline
\end{tabular}

Note: Standardized solutions are reported: ${ }^{*} \mathrm{p}<0.001$

\section{Limitations and Future Research}

The first limitation explicated in this study is the issue of generalizability of findings. This is because college student sample could be seen as a major limitation for this study even though most related studies have used students' samples. Student samples may be different from non students in the context of demographics such as income or social class and other socio-psychological variables (e.g., alienation, dogmatism, conservatism, status consciousness, cosmopolitanism, social responsibility, etc). Such differences might, in turn affect decision making styles and purchase preferences. Hence, it is also necessary that the CSI be tested on samples other than students if the instrument is to be used on the general population. Student samples as suggested in other studies (Douglas \& Craig, 1983; Andrews et al., 1991) are appropriate because they can be matched with respect to factors such as age, sex, education, etc. Secondly, the hypotheses need to be tested in different product categories. In the same sense, the shopping styles included in the CSI are also not product specific. Goldsmith et al. (1995) concluded that there have been calls for examining consumer innovativeness in different product categories. Furthermore, replication of this model in the context of other country settings would help determine if the proposed model as explicated among tertiary students in Botswana has universal application or is culture specific to Botswana. The limitations identified in this study could thus serve as fertile grounds for future research. Perhaps a more parsimonious version of the inventory with fewer scale dimensions that exhibits greater internal consistency could be developed and validated using confirmatory factor analysis. The abbreviated version of the original instrument reported in this article is a step in that direction. It is therefore necessary that the CSI be tested on samples other than students if the instrument is to be used on the general population. Thirdly, the study was cross-sectional as it was done at one point in time. This is a limitation and also an avenue for future research as future studies may examine longitudinal study. 


\section{References}

Andrews, J. C., Lysonski, S., \& Durvasula, S. (1991). Understanding cross cultural student perceptions of advertising in general: Implications for advertising educators and practitioners. Journal of Advertising, 20, 15-28. http://dx.doi.org/10.1080/00913367.1991.10673210

Bagozzi, R. P., \& Foxall, G. R. (1996). Construct validation of a measure of adaptive-innovative cognitive styles in consumption. International of Research in Marketing, 13(2), 201-13. http://dx.doi.org/10.1016/0167-8116(96)00010-9

Bennett, P. D., \& Kassarjian, H. H. (1972). Foundations of marketing series: Consumer Behaviour. New Jersey: Prentice Hall.

Bloch, P. H. (1995). Seeking the ideal form: product design and consumer response. Journal of Marketing, 59(3), 16-29. http://dx.doi.org/10.2307/1252116

Cottee, J., \& Wood, S. (2004). Families and innovative consumer behaviour: a triadic study of siblings and parents. Journal of Consumer Research, 31(1), 78-86. http://dx.doi.org/10.1086/383425

Cowart, K. O., Fox, G. L., \& Wilson, A. E. (2008). A structural look at consumer innovativeness and self congruences in new product purchases. Psychology \& Marketing, 25(12), 1111-30. http://dx.doi.org/10.1002/mar.20256

Darden, W. R, \& Ashton, D. (1974). Psychographic profiles of patronage preference groups. Journal of Retailing, 50(4), 99-112.

Douglas, S., \& Craig, C. S. (1983). International Marketing Research. Englewood Cliffs, NJ: Prentice Hall.

Gerbing, D. W., \& Anderson, J. C. (1988). An updated paradigm for scale development incorporating unidimensionality and its assessment. Journal of Marketing Research, 25, 186-92. http://dx.doi.org/10.2307/3172650

Goldsmith, R. E., Freiden, J. B., \& Eastman, J. K. (1995). The generality/specificity issue in consumer innovativeness research. Technovation, 15(10), 601-11. http://dx.doi.org/10.1016/0166-4972(95)99328-D

Hirschman, E. C. (1980). Innovativeness, novelty seeking and consumer creativity. Journal of Consumer Research, 7(3), 283-95. http://dx.doi.org/10.1086/208816

Hirschman, E. C. (1984). Experience seeking: a subjectivist perspective of consumption. Journal of Business Research, 12(1), 15-36. http://dx.doi.org/10.1016/0148-2963(84)90042-0

Hirunyawipada, T., \& Paswan, A. K. (2006). Consumer innovativeness and perceived risk: implications for high technology production adoption. Journal of Consumer Marketing, 23(4), 182-98. http://dx.doi.org/10.1108/07363760610674310 
Hofstede, G. (1980). Culture's consequences: International differences in work related value. Beverly Hills, CA: Sage Publications.

Im, S., Charlotte, H. M., \& Houston, M. B. (2007). Does innate consumer innovativeness relate to new product/service adoption behaviour. The intervening role of social learning via vicarious innovativeness. Journal of the Academy of Marketing Science, 35(1), 63-75. http://dx.doi.org/10.1007/s11747-006-0007-z

Lastovicka, J. L. (1982). On the validation of lifestyle traits: a review and illustration. Journal of Marketing Research, 19, 126-38. http://dx.doi.org/10.2307/3151537

Lysonski, S., Durvasula, S., \& Zotos, Y. (1996). Consumer decision making styles: a multi-country investigation. European Journal of Marketing, 30(12), 10-21. http://dx.doi.org/10.1108/03090569610153273

Midgley, D. F., \& Dowling, G. R. (1978). Innovativeness: The concept and its measurement: a questionable assumption. Journal of Consumer Research, 4(4), 229-42. http://dx.doi.org/10.1086/208701

Moschis, G. P. (1976). Shopping orientations and consumer uses of information. Journal of Retailing, 52, 61-70, 93.

Rangaswamy, A., \& Gupta, S. (1999). Innovation Adoption and Diffussion in the Digital Environment: Some Research opportunities. Working paper, E-Business Research Center, Penn State University, CA.

Roehrich, G. (2004). Consumer innovativeness concepts and measurements. Journal of Business Research, 57(6), 671-7. http://dx.doi.org/10.1016/S0148-2963(02)00311-9

Rogers, E. M., \& Shoemaker, F. F. (1971). Communication of Innovations: A cross-cultural approach (2nd ed.). New York, NY: The free Press.

Sheth, J. N., Newman, B. I., \& Gross, B. L. (1991). Consumption Values and Market Choices: Theory and Application. South Western, Cincinnati, $\mathrm{OH}$.

Sproles, E. K., \& Sproles, G. B. (1990). Consumer decision making styles as a function of individual learning styles. The Journal of Consumer Affairs, 24, 134-147. http://dx.doi.org/10.1111/j.1745-6606.1990.tb00262.x

Sproles, G. B. (1985). From perfectionism to fadism: measuring consumers decision making styles. In Schnittgrund, K. P. (Ed.), Proceedings, American Council on Consumer interest, ACCI, Columbia, MO, pp. 79-85.

Sproles, G. B., \& Kendall, E. L., (1986). A methodology for profiling consumers' decision making styles. The Journal of Consumer Affairs, 20(2), 267-279. http://dx.doi.org/10.1111/j.1745-6606.1986.tb00382.x

Steenkamp, J. E. M., Hofstede, F., \& Wedel, M. (1999). A cross-cultural investigation into the individualism and national cultural antecedents of consumer innovativeness. Journal of Marketing, 63, 55-69. http://dx.doi.org/10.2307/1251945 


\section{Macrothink}

Business and Management Horizons

ISSN 2326-0297 2013, Vol. 1, No. 2

Venkatraman, M. P. (1991). The impact of Innovativeness and innovation type on adoption. Journal of Retailing, 67(1), 51-67.

Venkatraman, M. P., \& MacInnis, D. J. (1985). An investigation of the epistemic and sensory exploratory behaviours of hedonic and cognitive consumers. Advances in Consumer Research, 12(1), 102-7.

Venkatraman, M. P., \& Price, L. L. (1990). Differentiating between cognitive and sensory innovativeness. Journal of Business Research, 20(4), 293-315. http://dx.doi.org/10.1016/0148-2963(90)90008-2

Wesley, S. C., Lettew, M., \& Woodside, A. (2006). Consumer decision making styles and mall shopping behaviour: building theory using exploratory data analysis and comparative method. Journal of Business Research, 59(5), 535-48. http://dx.doi.org/10.1016/j.jbusres.2006.01.005

Zuckerman, M. (1979). Sensation seeking Beyond the Optimal Level of Arousal. Hillsdale, NJ: Lawrence Erlbaum Associates.

\section{Copyright Disclaimer}

Copyright reserved by the author(s).

This article is an open-access article distributed under the terms and conditions of the Creative Commons Attribution license (http://creativecommons.org/licenses/by/3.0/). 